CEGfallis.pdf

$12 / 11 / 06$

\title{
Collective Epistemic Goals
}

\author{
Don Fallis \\ School of Information Resources \\ University of Arizona \\ fallis@email.arizona.edu
}

Author Posting. (c) Taylor \& Francis, 2007.

This is the author's version of the work. It is posted here by permission of Taylor \& Francis for personal use, not for redistribution.

The definitive version was published in Social Epistemology, Volume 21 Issue 3, July 2007. doi:10.1080/02691720701674106 (http://dx.doi.org/10.1080/02691720701674106) 


\section{Collective Epistemic Goals}

Abstract: We all pursue epistemic goals as individuals. But we also pursue collective epistemic goals. In the case of many groups to which we belong, we want each member of the group - and sometimes even the group itself - to have as many true beliefs as possible and as few false beliefs as possible. In this paper, I respond to the main objections to the very idea of such collective epistemic goals. Furthermore, I describe the various ways that our collective epistemic goals can come into conflict with each other. And I argue that we must appeal to pragmatic considerations in order to resolve such conflicts.

\section{Introduction}

Human beings pursue a number of different goals. For example, we want food, shelter, health, and happiness. But, in addition to these pragmatic goals, we also have epistemic goals. In particular, we want to have as many true beliefs as possible and as few false beliefs as possible. As William James $(1896 / 1979,24)$ nicely puts it, "we must know the truth; and we must avoid error - these are our first and great commandments as would-be knowers." In fact, this is the standard account of our epistemic goals in the epistemological literature (cf. Chisholm 1977, 14, Alston 1985, 59, Latus 2000).

From an epistemological perspective, achieving these epistemic goals is intrinsically valuable. But frequently, achieving these epistemic goals is primarily valuable as a means to achieving our pragmatic goals (cf. Goldman 1999, 73-75). In fact, our very survival can depend on our knowing the truth and avoiding error (cf. Godfrey-Smith 1991).

The epistemological literature on epistemic goals focuses almost exclusively on the epistemic goals of individuals. But some of our most important epistemic goals are collective epistemic goals. For example, we want juries to acquire true beliefs about the guilt of the defendant. We want consumers to acquire true beliefs about the safety and effectiveness of products. We want voters to acquire true beliefs about the views and qualifications of candidates. We want the scientific community to acquire true beliefs about how the world works. We want students and library patrons to acquire true beliefs on all sorts of subjects.

Furthermore, we often make important decisions that we think will allow us to achieve these collective epistemic goals (cf. Kitcher 1993, Goldman 1999, Fallis 2004). For example, we adopt rules of evidence to increase the likelihood that juries will acquire true beliefs. We pass truth-in-advertising laws to increase the likelihood that consumers will acquire true beliefs. We create collection development policies to increase the likelihood that library patrons will acquire true beliefs. Given the critical role that our collective epistemic goals can play in our everyday lives, understanding exactly what these goals are is not just of theoretical interest. 
In this paper, I suggest how to extend the standard account of the epistemic goals of individuals to the case of groups. In particular, our collective epistemic goals include summative goals for all of the members of a group and non-summative goals for the group itself. In addition, I briefly survey the various accounts of group belief upon which an account of non-summative collective epistemic goals depends.

I also respond to the main objections to the very idea of collective epistemic goals. These objections fall into two basic categories: First, even if it makes sense to talk about the epistemic goals of individuals, it is not clear that it makes sense to talk about the epistemic goals of groups. Second, standard worries about epistemic goals in general can become even more pressing when we shift our focus from individuals to groups.

Finally, I argue that we cannot ignore pragmatic considerations in giving an account of our collective epistemic goals. In addition to conflicting with our pragmatic goals at times, our collective epistemic goals can come into conflict with each other in various ways because of limits on our time and resources. I argue that we actually need to appeal to pragmatic considerations in order to resolve such conflicts between the epistemic goals themselves (cf. Fallis 2006). For example, the distribution of knowledge amongst the members of a group that we ought to aim for frequently depends on why the group needs this knowledge.

\section{Types of Collective Epistemic Goals}

As noted above, the standard account of our epistemic goals as individuals is that we want to have as many true beliefs as possible and as few false beliefs as possible. There is an obvious way to extend this account of the epistemic goals of individuals to an account of the epistemic goals of groups. Namely, we want the group to have as many true beliefs as possible and as few false beliefs as possible.

On the simplest account of group belief, a group believes $p$ if all (or at least most) of the members of the group believe $p$ (cf. Quinton 1976, 17). If this is the correct account of group belief, then our collective epistemic goal just is the following summative goal. Namely, we simply want each member of the group to have as many true beliefs as possible and as few false beliefs as possible. ${ }^{1}$

However, several philosophers have argued that this is not a plausible account of group belief. For example, Margaret Gilbert $(1989,257-260)$ has pointed out that there are cases where a group does not believe $p$ even though most of the members of the group believe $p$. Also, Philip Pettit $(2003,167)$ has argued that there are cases where a group believes $p$ even though most of the members do not believe $p$. As a result, several nonsummative accounts of group belief have also been proposed.

According to what we might call procedural accounts of group belief, a group believes $p$ if $p$ is taken (by at least certain members) to be the group view. For example, according

${ }^{1}$ This summative goal is the collective epistemic goal that Alvin Goldman (1999, 93-94) focuses on. 
to Gilbert (1989, 289), a group has a particular belief if "all or most members of the group have expressed willingness to let a certain view 'stand' as the view of the group." In a similar vein, Raimo Tuomela $(1995,314-316)$ claims that a group has a particular belief if certain "operative members" of the group (i.e., those members that are charged with determining the views of the group) adopt this view as the view of the group. ${ }^{2}$

There are also what we might call attribution accounts of group belief. For example, Deborah Tollefsen (2002) suggests that we simply take the intentional stance (a la Dennett 1987) toward organizations and other groups of people. Thus, a group has a particular belief if the attribution of this belief to the group is part of a successful interpretation of the behavior of the group (where a successful interpretation is one that allows us to explain and predict behavior). ${ }^{3}$

Under these non-summative accounts of group belief, it is sometimes possible for a group to have beliefs that are not just the sum of the beliefs of its members. In fact, a group might even have beliefs that none of its members have (and fail to have beliefs that all of its members have). As a result, the epistemic goals of a group are not necessarily reducible to the epistemic goals of its members. In such cases, we want the group itself to have as many true beliefs as possible and as few false beliefs as possible. In fact, there is an even more comprehensive collective epistemic goal that combines the summative and the non-summative. Namely, we want each member of the group and the group itself to have as many true beliefs as possible and as few false beliefs as possible.

\section{Worries about Collective Epistemic Goals}

The preceding account of our collective epistemic goals is a fairly straightforward extension of the standard account of our individual epistemic goals. But this account requires us to make two critical presuppositions. First, we have to presume that groups can have beliefs (since epistemic goals are typically goals with respect to beliefs). Second, we have to presume that groups can have goals. These presuppositions are unproblematic in the case of individuals, but it is not clear that they are warranted in the case of groups. In this section, I argue that groups can have beliefs and goals in a sufficiently robust sense to satisfy these presuppositions.

\section{a) Group Beliefs?}

We often attribute beliefs to groups. For example, we say that the jury believed that the defendant was guilty. However, it might be suggested that such attributions are simply useful fictions. One might plausibly take the position that something has to have a mind in order to have beliefs. And groups pretty clearly do not have minds (at least they do not

${ }^{2}$ This is actually just one of several types of group belief that Tuomela discusses.

${ }^{3}$ The notion of "objective knowledge" arguably provides another attribution account of group belief, at least for one particular group. According to Popper (1972), society as a whole knows $p$ as long as it has been written down and stored in a library. All that matters is that this knowledge could be retrieved. It does not matter whether anybody has actually retrieved it. 
have minds over and above the minds of their members). But, if groups do not have minds and, thus, do not really have beliefs, it is not clear that they can pursue the epistemic goal of having true beliefs.

This sort of worry about group belief does not present a problem for summative collective epistemic goals. Such goals just require that the individual members of the group can have beliefs. But this sort of worry does potentially present a problem for nonsummative collective epistemic goals, which require that the group itself can have beliefs. As I argue below, however, a group itself can have beliefs in the sense that is needed in order for it to have a non-summative collective epistemic goal.

As noted above, there are two main types of non-summative accounts of group belief. In the case of attribution accounts of group belief, it is primarily an empirical question whether it makes sense to attribute beliefs to a particular group. By contrast, in the case of procedural accounts, it is a conceptual question whether groups can have beliefs in the appropriate sense for them to have non-summative collective epistemic goals. Since I take this to be the hard case, I will focus on procedural accounts of group belief when non-summative collective epistemic goals are under discussion in this paper.

Groups certainly do not have beliefs in the same sense that individuals do (cf. Hakli 2006). But just like the beliefs of individuals, the "beliefs" of groups have consequences. For example, the "beliefs" of an organization guide the actions of that organization. Thus, just like the beliefs of individuals, we want these "beliefs" of groups to be true rather than false. For example, we want juries to return accurate verdicts even if there is no group mind that believes those verdicts to be true. Just like the true beliefs of individuals, the true "beliefs" of groups often have instrumental value.

Even so, the "beliefs" of groups might still differ from the beliefs of individuals in a way that is important for epistemology. In particular, it has been suggested that groups cannot form beliefs for good epistemic reasons (e.g., on the basis of evidence). On most accounts of group belief, the "beliefs" of a group are under the voluntary control of the group (or at least the voluntary control of the members of the group). But as Bernard Williams $(1973,148)$ points out, "if I could acquire a belief at will, I could acquire it whether it was true or not." Thus, the worry is that the "beliefs" of a group will tend to be determined by the pragmatic goals of the group (cf. Meijers 2003, McMahon 2003). For example, on Gilbert's account of group belief, the members of a group might easily let something stand as the group view for purely pragmatic reasons. ${ }^{4}$

But this does not show that groups cannot form beliefs for good epistemic reasons. On procedural accounts of group belief, the "beliefs" of groups are essentially like the judgments of individuals. The judgments of individuals are under their voluntary control. But we typically want these judgments to be true rather than false. The judgments of individuals are sometimes influenced by pragmatic considerations (cf. Gilbert 1989, 312313). But individuals can also make judgments for good epistemic reasons. Similarly,

${ }^{4}$ On attribution accounts of group belief as well, there might be purely pragmatic reasons for why a group has a particular belief. 
the members of a group can let something stand as the view of the group for good epistemic reasons (cf. Mathiesen 2006, 165-168). ${ }^{5}$ Thus, it still makes sense to talk about collective epistemic goals. In fact, it is often possible for a group to better achieve its epistemic goals than any of the members of the group (cf. Goldman 1999, 81-82).

\section{b) Collective Goals?}

We often attribute goals to groups. For example, we say that the team wanted to win the championship. However, it might be suggested that such attributions are also only useful fictions and that groups do not really have goals, much less epistemic goals. However, many philosophers (e.g., Gilbert 1989, 362, Tollefsen 2002, 401) have argued that groups can have goals beyond the goals of the members along the same lines that they can have beliefs beyond the beliefs of the members. In fact, procedural accounts of collective goals would seem to be even less controversial than procedural accounts of group beliefs. Taking something as a goal (possibly after some deliberation) is how individuals come to have many of their goals.

In any event, for purposes of this paper, I am more interested in what the goal is than in who has the goal. Even if groups cannot have goals for themselves, it still makes sense to talk about collective epistemic goals. An epistemic goal need not be a goal that one has for oneself. It can also be a goal that one individual has for another individual. For example, a teacher will typically have epistemic goals for her student. In a similar vein, an epistemic goal can be a goal that an individual has for a group. For example, a librarian will typically have epistemic goals for her patrons. In fact, the members of the group might even share the goal that the members of the group acquire (or that the group itself acquires) true beliefs. Several authors (e.g., Miller 1995, Kutz 2000) refer to such shared goals as the collective goals of the group. ${ }^{6}$

\section{Worries about Epistemic Goals in General}

Thus, groups can have beliefs and goals in the sense required by an account of our collective epistemic goals. But there is another respect in which such an account is vulnerable. The account of our collective epistemic goals that I have offered is simply an extension of the standard account of our individual epistemic goals. And a number of criticisms have been raised in the epistemological literature about this standard account. In fact, as I discuss in this section, these criticisms are even more worrisome when we shift our focus from individuals to groups. But I argue that these criticisms can be effectively addressed for both individual epistemic goals and for collective epistemic goals.

\section{a) Beyond True Belief and Error Avoidance}

\footnotetext{
${ }^{5}$ As I will discuss in the final section of this paper, pragmatic considerations do play a role in determining exactly what our epistemic goals are. But this applies to the epistemic goals of individuals as well as to the epistemic goals of groups.

${ }^{6}$ These collective goals are a central part of their analysis of collective action.
} 
The literature on epistemic goals tends to focus on the goal of acquiring true belief and the goal of avoiding error. However, it might be suggested that this account of our epistemic goals is too restrictive. We seem to pursue many other epistemic goals beyond the goal of having many true beliefs and the goal of having few false beliefs (cf. Nozick 1993, 67, Kvanvig 2003, 187). For example, we also want beliefs that are justified, that have explanatory power, that provide understanding and wisdom, etc.

One possible defense of the standard account is to claim that these other epistemic goals are only instrumentally valuable. For example, some philosophers (e.g., BonJour 1985, 7-8) claim that justification is only valuable as a means to the goal of having many true beliefs and the goal of having few false beliefs. ${ }^{7}$ However, it seems rather implausible that this applies to every epistemic goal other than the goal of acquiring true beliefs and the goal of avoiding error. It seems unlikely that understanding, for example, is only valuable as a means to true belief. Just like true belief, understanding seems to have intrinsic epistemic value. Also, just like true belief, understanding can be valuable as a means to achieving other goals that we have. Thus, we probably want an account of epistemic goals that incorporates a plurality of epistemic goals.

In the case of individuals, we can easily extend our story to include these other epistemic goals. The question arises, however, whether we can extend our story in this way in the case of groups. Individuals can certainly acquire justified beliefs and gain understanding. But it is not immediately clear that groups can do so.

As Frederick Schmitt $(1994,282)$ suggests, the beliefs of a group can be justified in a reliabilist sense. The procedure used to take something to be the view of the group just needs to be one that is reliable. For example, a procedure that creates a group view by taking a weighted average of the views of the members of the group can be reliable (cf. Goldman 1999, 81-82). In fact, the group view created by this procedure can be more likely to be correct than the views of any of the individual members. However, the fact that a belief is produced by a reliable process probably is something that is only instrumentally valuable (cf. Zagzebski 2003, 14). Thus, the fact that groups can be justified in this sense does not really extend our account of collective epistemic goals.

But there are other senses of justification that may not simply be valuable as a means to the goal of having many true beliefs and the goal of having few false beliefs. For example, having reasons for one's beliefs seems to have intrinsic epistemic value. However, Schmitt (1994, 277-282) has also argued that such internalist justification cannot be had by groups. As noted above, a group could fail to believe $p$ when all of its members do. Similarly, a group could fail to have a reason to believe $p$ when all of its members do. But, as I argue below, this does not show that it is impossible for the beliefs of a group to be justified in an internalist sense.

There are at least two reasons why a group could fail to have a reason to believe something that it believes. First, a group could fail to have a reason simply because it has

${ }^{7}$ Of course, many philosophers (e.g., Zagzebski 2003) also think that knowledge is more valuable than true belief. 
not gotten around to explicitly adopting something as its reason. But even in the individual case, in order to be justified, an individual does not necessarily have to have brought reasons to mind. Internalist theories of justification typically require only potential awareness, rather than actual awareness, of reasons. In other words, an individual just has to be able to bring the reasons to mind if prompted. But a group might also be able to "bring the reasons to mind" if prompted (i.e., by explicitly adopting as its reason the reason that its members have).

Second, a group could also fail to have a reason because the various members of the group have very different reasons for believing $p$. For example, a court made up of several judges, such as the Supreme Court, may agree on a particular decision, but the individual judges may have reached that decision for very different reasons (cf. Pettit 2003, 168-170). As a result, even if the group tries to explicitly adopt something as its reason, it may be unable to do so. But this just shows that it can be more difficult for a group to be justified in its beliefs. It does not show that it is impossible for a group to be justified. $^{8}$

In addition to having justified beliefs, groups might even be able to gain understanding or even wisdom. Having understanding is typically cashed out in terms of having true beliefs with certain properties, such as explanatory power and coherence (cf. Kvanvig 2003, 188-203). Being wise is typically cashed out in terms of having true beliefs about certain topics, such as how to live well (cf. Ryan 1999). If groups can have beliefs at all, it is not clear why they could not have beliefs with such properties or about such topics. Thus, it is not immediately clear why groups could not have understanding or be wise. More work certainly needs to be done on this issue. But, while it may be more difficult for a group to do so, it is not immediately clear why a group could not achieve such epistemic goals. ${ }^{9}$

So, an account of collective epistemic goals might be extended to incorporate many of these other epistemic goals. But, as Goldman $(1999,24)$ suggests, true belief is clearly our "dominant epistemic goal." Thus, in the remainder of this paper, I will continue to focus on the goal of having many true beliefs (and the goal of having few false beliefs).

\section{b) Degrees of Belief}

There is another respect in which the standard account of our epistemic goals might be too restrictive. This account focuses on the truth or falsity of categorical beliefs. But people also have degrees of belief in propositions (cf. Resnik 1987, 69). In the case of individuals, we can easily extend our story to include epistemic goals characterized in terms of degrees of belief. For example, we want to have a high degree of belief in true propositions and a low degree of belief in false propositions (cf. Goldman 1999, 90).

\footnotetext{
${ }^{8}$ In addition, even if the various members agree on a reason, they might disagree about why it is a good reason (cf. Schmitt 1994, 278-279). If this is also required for justification, then it is even more difficult for a group to be justified in its beliefs.

${ }^{9}$ It might also be the case that it is less valuable for a group to achieve such epistemic goals.
} 
However, even someone who thinks that a group can have epistemic goals involving categorical beliefs might not think that a group can have epistemic goals involving degrees of belief. For example, according to Pettit $(2003,182)$, a group "is incapable of forming degrees of belief ... its beliefs are recorded as on-off judgments."

However, an individual's degree of belief in a proposition is standardly inferred from a series of dichotomous choices over lotteries (cf. Resnik 1987, 69). There is no reason to think that a group could not make the same sorts of choices. In other words, if a group can have categorical beliefs (e.g., about whether one alternative is better than another), it can also potentially have degrees of belief. Thus, we might also want groups to have a high degree of belief in the truth. In the remainder of this paper, however, I will continue to focus on epistemic goals involving categorical beliefs.

\section{c) Doxastic Agency}

Finally, it might be suggested that it does not make sense to study our epistemic goals since there seems to be no way for us to achieve such goals. After all, we can rarely adopt a belief — much less a justified true belief — simply because we want to (cf. Heil 1983, 357). In other words, our beliefs are typically not under our voluntary control. But, as noted above, group beliefs are typically under the voluntary control of the group. ${ }^{10}$ Thus, worries about doxastic agency are actually less pressing in the case of groups than in the case of individuals.

In any event, while we may not always be able to achieve epistemic goals directly (as a result of doxastic involuntarism), we can and do try to achieve epistemic goals indirectly (cf. Heil 1983, 362-363). For example, if we read the New York Times rather than the National Enquirer, we are somewhat more likely to end up with true beliefs. Likewise, in the important policy decisions that partially motivated our interest in collective epistemic goals, we evaluate policies that are indirect means of assuring that individuals and groups end up with true beliefs. For example, certain types of evidence cannot be presented at jury trials so that juries will be more likely to end up with true beliefs about the guilt of the defendant (Goldman 1999, 292-295).

\section{Epistemic Goals and Pragmatic Goals}

The epistemological literature typically discusses our epistemic goals in isolation from the rest of our goals. In this section, I consider two reasons why we cannot ignore our pragmatic goals as we give an account of our collective epistemic goals. First, our epistemic goals can come into conflict with other goals that we have. Second, our epistemic goals can come into conflict with each other, and it is not possible to resolve such conflicts without appealing to other goals that we have. These are both critical issues for an account of collective epistemic goals because, as I discuss below, the potential for conflict is much greater for groups than for individuals.

\footnotetext{
${ }^{10}$ Mathiesen $(2006,165)$ claims that at least some group beliefs are not under the voluntary control of the group.
} 


\section{a) Knowledge with Bad Consequences}

There are at least two ways in which acquiring more true beliefs can have bad consequences (cf. Nozick 1993, 69, Fallis 2004, 103). First, the cost of acquiring the true beliefs might exceed the benefit of having the true beliefs. For example, while a fullbody CT examination can certainly provide useful knowledge (e.g., early detection of diseases), the radiation involved in the examination can significantly increase a person's risk of getting cancer (cf. Brenner and Elliston 2004). Second, the cost of having the true beliefs might exceed the benefit of having the true beliefs. For example, individuals who have an inflated view of their abilities tend to be happier than those who have accurate self-images (cf. Taylor and Brown 1988). Thus, the goal of having many true beliefs (and few false beliefs) may not be our goal all things considered.

Furthermore, there are additional ways in which achieving our collective epistemic goals might have bad consequences. For example, there are sometimes opportunity costs if too many people have particular true beliefs. In particular, we might end up with more experts on a particular subject than the economy can support (cf. Hollis 1982, 240-241). Also, if some people acquire more true beliefs than others, it can increase the knowledge divide between the information haves and the information have-nots (cf. Fallis 2007, 37$38)$.

Since acquiring true beliefs and avoiding error can lead to bad consequences, it might be suggested that we should not be worrying about epistemic goals at all. Instead, we should simply be trying to achieve whatever doxastic goals lead to the best consequences (cf. Goldman 2002, 218-220). Indeed, if acquiring true beliefs and avoiding error regularly led to bad consequences, we would not have much reason to try to give an account of our epistemic goals. In fact, there would be much less motivation for philosophers to study epistemology at all. However, those cases where achieving our epistemic goals leads to bad consequences are arguably exceptional (cf. Fallis 2007, 35-40). In the vast majority of cases, good epistemic outcomes tend to be good outcomes all things considered. Thus, even setting aside its theoretical interest, it is still very useful to understand exactly what counts as a good epistemic outcome.

\section{b) Conflicting Epistemic Goals}

Unfortunately, the standard account of our epistemic goals does not tell us everything that we need to know about what counts as a good epistemic outcome. Even if we are only concerned with having true beliefs and avoiding error, the standard account does not tell us everything that we want to know about our epistemic goals. As James (1896/1979, 24) points out, the goal of having more true beliefs and the goal of having fewer false beliefs are "two separable" goals. And, because we have limited time and resources, these two goals will often come into conflict. ${ }^{11}$ That is, we might have to choose between a course of action that leads to more true beliefs and another course of action that leads to

\footnotetext{
${ }^{11}$ If we have other epistemic goals (e.g., gaining understanding), then there is the potential for many other conflicts.
} 
fewer false beliefs. ${ }^{12}$ In addition, we might have to choose between a course of action that leads to more true beliefs on one topic (e.g., physics) and another course of action that leads to more true beliefs on another topic (e.g., philosophy). But the standard account of our epistemic goals does not tell us what to do when such conflicts arise.

Conflicts between the goal of having more true beliefs and avoiding error can arise for groups as well as individuals. But there are also additional conflicts that can arise specifically in the case of groups. In fact, these conflicts can arise even if there is only a single epistemic goal (e.g. having more true beliefs). For example, the goal of member $\mathbf{X}$ having more true beliefs can come into conflict with the goal of member $\mathbf{Y}$ having more true beliefs. In order to resolve such conflicts, we need to be able to say how true beliefs should be distributed among the members of the group (cf. Fallis 2004, 105-109, Fallis $2006,181)$. The summative collective epistemic goal does not tell us how to resolve such conflicts.

Furthermore, just as the goal of one member having more true beliefs can come into conflict with the goal of another member having more true beliefs, the goal of the group itself having more true beliefs can come into conflict with the goal of its members having more true beliefs. While the beliefs of a group are often highly correlated with the beliefs of its members, this is not required by these accounts of group belief (cf. Gilbert 1989, 304-306). As a result, it is possible for a group to have many true beliefs and few false beliefs while its members are mired in ignorance and error. In fact, in order for society to arrive at the truth on a particular topic, it may be necessary for many members of society to have false beliefs on that topic (cf. Mill 1859/1978, 36). ${ }^{13}$ In a similar vein, the scientific community is more likely to discover the true theory in some area if a significant number of researchers are testing theories that are unlikely to be true (cf. Kuhn 1977, 332, Kitcher 1993, 303-389, Goldman 1999, 254-260). However, the comprehensive collective epistemic goal (that combines the summative and the nonsummative) does not tell us whether to give greater weight to the goals of the group or to the goals of the members.

In addition to conflicts between a group and its members, there can essentially be conflicts between the group and itself, or rather between the group and another group with exactly the same members. ${ }^{14}$ For example, as Quinton $(1976,21)$ points out, "it is possible that the parish council of a given village should have as its members all and only those who are members of the church bell-ringers of that village." Since these two groups have different missions and different procedures for adopting beliefs, they can easily have different beliefs. The parish council might believe that the church needs a

${ }^{12}$ Ideally, we would have all possible true beliefs and absolutely no false beliefs. In that case, there would be not conflict. But this is clearly not feasible (cf. Latus 2000, 32). ${ }^{13}$ John Stuart Mill $(1859 / 1978,36)$ claims that "if opponents of all-important truths do not exist, it is indispensable to imagine them and supply them with the strongest arguments which the most skillful devil's advocate can conjure up." However, it may not be possible to come up with such arguments unless some people actually have false beliefs on the topic.

${ }^{14}$ There might also be conflicts between two groups with less extensive overlaps. 
new roof while bell-ringers have no opinion on the matter. As a result, the epistemic goals of two different groups can potentially come into conflict even if the two groups have the very same members. For example, we might have to choose between a course of action that leads to more true beliefs for the parish council and another course of action that leads to more true beliefs for the bell-ringers.

Finally, there is another important conflict that can potentially arise for groups. As Goldman $(1999,161)$ points out, there are essentially two ways to increase the amount of knowledge that a group possesses. First, new knowledge can be discovered. Second, existing knowledge can be disseminated more widely within the group. However, the summative collective epistemic goal does not tell us what to do when the goal of discovering new knowledge conflicts with the goal of disseminating existing knowledge more widely (cf. Fallis 2004, 109). This sort of conflict between having more knowledge types and having more knowledge tokens does not arise if we are focused on the epistemic goals of a single individual. ${ }^{15}$

\section{c) Resolving the Conflicts}

Some philosophers have claimed that there is an epistemologically preferred way to resolve such conflicts. Take, for example, a conflict between the goal of having true beliefs and the goal of avoiding error. René Descartes $(1641 / 1996,12)$ and David Hume $(1748 / 1977,111)$ claim that avoiding error is always more important than having additional true beliefs. By contrast, James (1896/1979, 31-32) seems to think that having additional true beliefs is more important than avoiding error. This is suggested by his claim that "a rule of thinking which would absolutely prevent me from acknowledging certain kinds of truth if those kinds of truth were really there, would be an irrational rule." However, many philosophers (e.g., Levi 1962, 57, Lehrer 1975, 71, Godfrey-Smith 1991) have argued that there is no preferred way to resolve such conflicts. ${ }^{16}$ Instead, the resolution of such conflicts depends on exactly why we have the particular epistemic goals that we have.

While achieving these two epistemic goals is arguably intrinsically valuable, it is often a means to some further end. Sometimes this further end is an epistemic end (e.g., avoiding error today may lead to more true beliefs tomorrow). However, it is often the case that this further end is a pragmatic end. As a result, conflicts between these two epistemic goals must often be resolved on the basis of pragmatic considerations. For example, it is reasonable for a scientist doing medical research to be much more concerned with error avoidance than a student taking an exam because the stakes are higher. Similarly, it is reasonable for the jury in a murder trial to be much more concerned with error avoidance than the jury picking the best pumpkin at the state fair.

${ }^{15}$ This is not necessarily just another potential conflict between the goals of a group and the goals of its members. New knowledge may have been discovered even if the group itself does not have the knowledge.

${ }^{16}$ Several philosophers of science (e.g., Kuhn 1977, 324, Maher 1993, 210) have made similar points about other epistemic goals. 
Some philosophers have also claimed that there is a preferred way to distribute true beliefs among the members of a group. For example, according to Goldman $(1999,93)$, one distribution of true beliefs is better than another if the total number of true beliefs held by the members of the group is greater. However, how true beliefs should be distributed among the members of a group must often be determined by pragmatic considerations. For example, we might want knowledge to be distributed throughout society in a way that facilitates the effective functioning of the economy (cf. Hayek 1945). Similarly, a captain wants knowledge to be distributed among her crew in a way that facilitates the effective functioning of the ship (cf. Hutchins 1995). In fact, Goldman $(1999,96)$ himself admits that "a veritistically good practice for such an enterprise would promote the required distribution of knowledge, even if that does not translate into a high average knowledge across the whole team."

In addition, some philosophers have essentially claimed that there is a preferred way to resolve conflicts between having more knowledge types and having more knowledge tokens. For example, Goldman (1999, 93-94) is solely concerned with maximizing the number of knowledge tokens possessed by the group. ${ }^{17}$ By contrast, Sir Karl Popper (1972, 107-108) was more concerned with maximizing the number of knowledge types possessed by the group. This is suggested by his focus on the amount of "objective knowledge"-which includes things like "the contents of journals, books, and libraries" - that has been discovered. It does not matter how many people actually possess this knowledge. ${ }^{18}$ However, such conflicts again must often be resolved on the basis of pragmatic considerations. In some contexts, the number of knowledge types is more important. For example, in scientific research, the goal is to discover as much new knowledge as possible. ${ }^{19}$ However, in other contexts, the number of knowledge tokens is more important. For example, it is important for public health that information about sexually transmitted diseases be widely disseminated.

In order for us to make decisions where epistemic consequences for many people are at stake, we have to be able to resolve these sorts of conflicts between our collective epistemic goals. And, as I have argued, we will often have to resolve such conflicts on the basis of pragmatic considerations. Thus, even setting aside those few cases where achieving our epistemic goals leads to bad consequences, we cannot treat our epistemic goals completely in isolation from our pragmatic goals.

One might worry that using pragmatic considerations to resolve such conflicts "would lead down the path toward abandoning the specialized, veritistic mission of epistemology in favor of a more purely pragmatic enterprise" (Goldman 1999, 95). But such a worry would be misplaced. Pragmatic considerations are only being used here to pick one

${ }^{17}$ Strictly speaking, Goldman focuses on maximizing the average number of knowledge tokens possessed by the members of the group.

${ }^{18}$ In order to really count as knowledge though, this "objective knowledge" probably needs to be accessible to the members of the group.

${ }^{19}$ Successful scientific research also requires the dissemination of existing knowledge among the members of the scientific community. However, such dissemination is primarily valuable as a means to the discovery of new knowledge. 
possible resolution from amongst several epistemically permissible resolutions (cf. Fallis 2006, 180). For example, pragmatic considerations are being used to determine which topics we ought to acquire true beliefs about. Also, pragmatic considerations are being used to determine which members of the group ought to acquire these true beliefs. Pragmatic considerations are not being used to determine what we ought to believe. If we were to believe things simply because doing so led to the best consequences, we would be abandoning epistemology (cf. Fallis 2006, 180).

\section{Conclusion}

We all pursue epistemic goals as individuals. But we also pursue collective epistemic goals. In the case of many groups to which we belong, we want each member of the group - and sometimes even the group itself - to have as many true beliefs as possible and as few false beliefs as possible. In this paper, I have responded to the main objections to the very idea of such collective epistemic goals. Furthermore, I have described the various ways that our collective epistemic goals can come into conflict with each other. And I have argued that we must appeal to pragmatic considerations in order to resolve such conflicts.

\section{References}

- Alston, William. 1985. "Concepts of Epistemic Justification." Monist 68:57-89.

- BonJour, Laurence. 1985. The Structure of Empirical Knowledge. Cambridge: Harvard.

- Brenner, David J. and Carl D. Elliston. 2004. "Estimated Radiation Risks Potentially Associated With Full-Body CT Screening." Radiology 232:735-38.

- Chisholm, Roderick. 1977. Theory of Knowledge. Englewood Cliffs, New Jersey: Prentice-Hall.

- Dennett, Daniel. 1987. The Intentional Stance. Cambridge: MIT.

- Descartes, René. 1641/1996. Meditations on First Philosophy. Cambridge: Cambridge.

- Fallis, Don. 2004. "Epistemic Value Theory and Information Ethics." Minds and Machines 14:101-17.

- Fallis, Don. 2006. "Epistemic Value Theory and Social Epistemology." Episteme 2:177-88.

- Fallis, Don. 2007. "Epistemic Value Theory and the Digital Divide." Pp. 29-46 in Information Technology and Social Justice, eds. Emma Rooksby and John Weckert. Hershey, Pennsylvania: Idea Group.

- Gilbert, Margaret. 1989. On Social Facts. London: Routledge.

- Goldman, Alvin I. 1999. Knowledge in a Social World. New York: Oxford.

- Goldman, Alvin I. 2002. "Reply to Commentators." Philosophy and Phenomenological Research 64:215-27.

- Godfrey-Smith, Peter. 1991. "Signal, Decision, Action." Journal of Philosophy 88:709-22.

- Hakli, Raul. 2006. "Group Beliefs and the Distinction Between Belief and Acceptance." Cognitive Systems Research 7:286-97. 
- Hayek, F. A. 1945. "The Use of Knowledge in Society." American Economic Review 35:519-30.

- Heil, John. 1983. "Doxastic Agency." Philosophical Studies 43:355-64.

- Hollis, Martin. 1982. "Education as a Positional Good." Journal of Philosophy of Education 16:235-44.

- Hume, David. 1748/1977. An Enquiry Concerning Human Understanding. Indianapolis: Hackett.

- Hutchins, Edwin. 1995. Cognition in the Wild. Cambridge: MIT.

- James, William. 1896/1979. The Will to Believe and Other Essays in Popular Philosophy. Cambridge: Harvard.

- Kitcher, Philip. 1993. The Advancement of Science. New York: Oxford.

- Kuhn, Thomas S. 1977. "Objectivity, Value Judgment, and Theory Choice." Pp. 320-339 in The Essential Tension, Chicago: University of Chicago.

- Kutz, Christopher. 2000. "Acting Together." Philosophy and Phenomenological Research 61:1-31.

- Kvanvig, Jonathan L. 2003. The Value of Knowledge and the Pusuit of Understanding. Cambridge: Cambridge.

- $\quad$ Latus, Andrew. 2000. "Our Epistemic Goal." Australasian Journal of Philosophy 78:28-29.

- Lehrer, Keith. 1975. "Reason and Consistency." Pp. 57-74 in Analysis and Metaphysics, ed. Keith Lehrer. Dordrecht: Reidel.

- Levi, Isaac. 1962. "On the Seriousness of Mistakes." Philosophy of Science 29:47-65.

- Maher, Patrick. 1993. Betting on Theories. New York: Cambridge.

- Mathiesen, Kay. 2006. "The Epistemic Features of Group Belief." Episteme 2:161-75.

- McMahon, Christopher. 2003. "Two Modes of Collective Belief." Protosociology 18-19:347-62.

- Meijers, Anthonie. 2003. "Why Accept Collective Beliefs? Reply to Gilbert." Protosociology 18-19:377-88.

- Mill, John S. 1859/1978. On Liberty. Indianapolis: Hackett.

- Miller, Seumas. 1995. "Intentions, Ends and Joint Action." Philosophical Papers 24:51-66.

- Nozick, Robert. 1993. The Nature of Rationality. Princeton: Princeton.

- Pettit, Philip. 2003. "Groups With Minds of Their Own." Pp. 167-93 in Socializing Metaphysics, ed. Frederick F. Schmitt. Lanham, Maryland: Rowman \& Littlefield.

- Popper, Karl. 1972. Objective Knowledge. Oxford: Oxford.

- Quinton, Anthony. 1976. "Social Objects." Proceedings of the Aristotelian Society 76:1-27.

- Resnik, Michael D. 1987. Choices. Minneapolis: University of Minnesota.

- Ryan, Sharon. 1999. "What Is Wisdom?" Philosophical Studies 93:119-39.

- Schmitt, Frederick. 1994. "The Justification of Group Beliefs." Pp. 257-87 in Socializing Epistemology, ed. Frederick Schmitt. Lanham, Maryland: Rowman and Littlefield. 
- Taylor, Shelly E. and Jonathon D. Brown. 1988. "Illusion and Well-Being: A Social Psychological Perspective on Mental Health." Psychological Bulletin 103:193-210.

- Tollefsen, Deborah. 2002. "Organizations as True Believers." Journal of Social Philosophy 33:395-410.

- Tuomela, Raimo. 1995. The Importance of Us. Stanford: Stanford.

- Williams, Bernard. 1973. "Deciding to Believe." Pp. 136-51 in Problems of the Self, Cambridge: Cambridge.

- Zagzebski, Linda. 2003. "The Search for the Source of Epistemic Good." Metaphilosophy 34:12-28. 